\title{
Is it Fair to Blame Bacteria Alone for the High Mortali- ty rate of Neonatal Sepsis?
}

\author{
Zina Alshami* \\ University of Kufa, Iraq \\ *Corresponding author: Zina Alshami, University of Kufa, Iraq
}

\begin{tabular}{|c|c|}
\hline ARTICLE INFO & ABSTRACT \\
\hline Received: April 27, 2019 & \multirow{3}{*}{$\begin{array}{l}\text { Even with the remarkable advances in supportive care and in understanding the causes } \\
\text { and pathogenesis of sepsis and its associated immune response, sepsis remains the major cause } \\
\text { of neonatal morbidity and mortality, especially among premature infants. Neonatal sepsis is a } \\
\text { multifactorial syndrome that needs a careful diagnosis and interpretation, treatment of such } \\
\text { case may require more than just an antibiotic therapy, considering other options such as blood } \\
\text { apheresis might be helpful. Isolation of infectious agents accompanied by checking for neonates' } \\
\text { genetic disorders will have a positive impact on lowering the rate of mortality. }\end{array}$} \\
\hline Published: 慧 April 30, 2019 & \\
\hline $\begin{array}{l}\text { itation: Zina Alshami. Is it Fair to } \\
\text { lame Bacteria Alone for the High Mor- } \\
\text { ality rate of Neonatal Sepsis?. Biomed } \\
\text { Sci \& Tech Res } 17(4)-2019 \text {. BJSTR. }\end{array}$ & \\
\hline
\end{tabular}

MS.ID.003028.

Keywords: Neonatal sepsis; Bacteria; Genetic disorders; Antibiotics

\section{Opinion}

Even with the remarkable advances in supportive care and in understanding the causes and pathogenesis of sepsis and its associated immune response, sepsis remains the major cause of neonatal morbidity and mortality, especially among premature infants. The world health organization (WHO) reported that $7 \%$ of mortality in children under 5 years and $15 \%$ in neonates was related to sepsis and meningitis in 2016 [1]. A new definition of maternal sepsis was issued in 2016 by the WHO, namely: "Maternal sepsis is a life-threatening condition defined as organ dysfunction resulting from infection during pregnancy, childbirth, post-abortion or postpartum" [1]. This definition comes along with the results of several studies who found that, sepsis frequently occurs in neonates due to infection with Group B Streptococci and Escherichia coli, which account for approximately $70 \%$ of infections combined. Additional pathogens which account for the remaining cases are Streptococcus pneumoniae, Staphylococcus aureus, Enterococcus spp., Gramnegative enteric bacilli such as Enterobacter spp., Haemophilus influenza [2].

In fact, the mere isolation of pathogens from neonates with sepsis is not enough to accuse infectious agents for being the main risk factor that lead to neonate subsequent death as stated. Actually, Sepsis is a complex disease resulting from the interaction of a person's genotype with environmental factors. Septic neonates have an upregulation and obvious decline of several genes, which involved in innate immunity (IL1R2, ILRN, and SOCS3) [3]. In addition, there are genotype specificity that can be associated with a significant increase in risk of developing severe sepsis like Genotypes GG of rs2569190 (the CD14 gene) and AT of rs4073 (the IL8 gene) [4]. Genotype AG of rs1800629 (the LTA gene) and genotypes CC and CT of rs1341023 (the BPIgene) were associated with a significantly increased risk of developing Gram-negative sepsis [5]. Truthfully, Genetic variability plays a big role in sepsis as well as the risk of having disease due to specific pathogens. Same pathogen isolated in sepsis cases can play a significant role in developing the immune system defenses in health neonates.

So, in order to manage neonatal sepsis, we are in need for a new developing a new guidelines and preventive strategies based on early diagnosis of neonatal genetic disorders as a predisposing factor for the development of different kinds of infections. Future medical research should focus on reducing the application and duration of antibiotics for neonatal sepsis to decrease the emergence and dissemination of resistant bacterial strains. Multidrug resistant pathogens is one of the challenging problems to the effective management among neonatal sepsis, therefore, wise use of antibiotics will aid in reducing drug resistance among resistant pathogens and emerging of new resistant strains. Empirical therapy options should be carefully chosen especially in case of neonatal sepsis caused by Methicillin 
resistant Staphylococcus aureus (MRSA) strains. Although the use of Vancomycin is effective in empiric therapy of neonatal sepsis, prolonged use of Vancomycin may lead to emerging of the difficult to treat Vancomycin resistant Staphylococcus aureus (VRSA) strains [6]. Empirical use of antibiotics may lead to other complications such as invasive candidiasis, necrotizing enterocolitis, increased antimicrobial resistance, late-onset sepsis, and death [7].

Death of neonates might not be due to sepsis alone but rather due to the side effect of antibiotics as in the case of Disseminated intravascular coagulation (DIC), the complication of using bactericidal antibiotic for treatment of Gram-negative bacterial infections. DIC is most commonly observed in severe sepsis and septic shock, the development and severity of DIC correlate with mortality in severe sepsis [8]. In conclusion, neonatal sepsis is a multifactorial syndrome that needs a careful diagnosis and interpretation, treatment of such case may require more than just an antibiotic therapy, considering other options such as blood apheresis might be helpful. Isolation of infectious agents

\section{ISSN: 2574-1241}

DOI: 10.26717/BJSTR.2019.17.003028

Zina Alshami. Biomed J Sci \& Tech Res

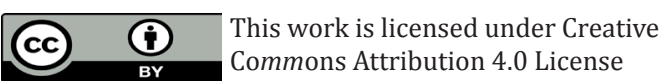

Submission Link: https://biomedres.us/submit-manuscript.php accompanied by checking for neonates' genetic disorders will have a positive impact on lowering the rate of mortality.

\section{Conflict of Interest}

The author declares no conflict of interest.

\section{References}

1. (2018) WHO Sepsis Technical Expert Meeting - Meeting report. Geneva: World Health Organization License: CC BY-NC-SA 3.0 IGO.

2. Simonsen KA, Anderson Berry AL, Delair SF, Davies HD (2014) Earlyonset neonatal sepsis. Clinical microbiology reviews 27(1):21-47.

3. Meng Y, Cai XH, Wang L (2018) Potential Genes and Pathways of Neonatal Sepsis Based on Functional Gene Set Enrichment Analyses. Computational and mathematical methods in medicine.

4. Esposito S, Zampiero A, Pugni L, Tabano S, Pelucchi C, et al. (2014) Genetic polymorphisms and sepsis in premature neonates. PlOS One 9(7): e101248.

5. Tripathi N, Cotton CM, Smith PB (2012) Antibiotic use and misuse in the neonatal intensive care unit. Clinics in perinatology 39(1):61-68.

6. Wynn JL, Wong HR (2010) Pathophysiology and treatment of septic shock in neonates. Clinics in perinatology 37(2): 439-479.

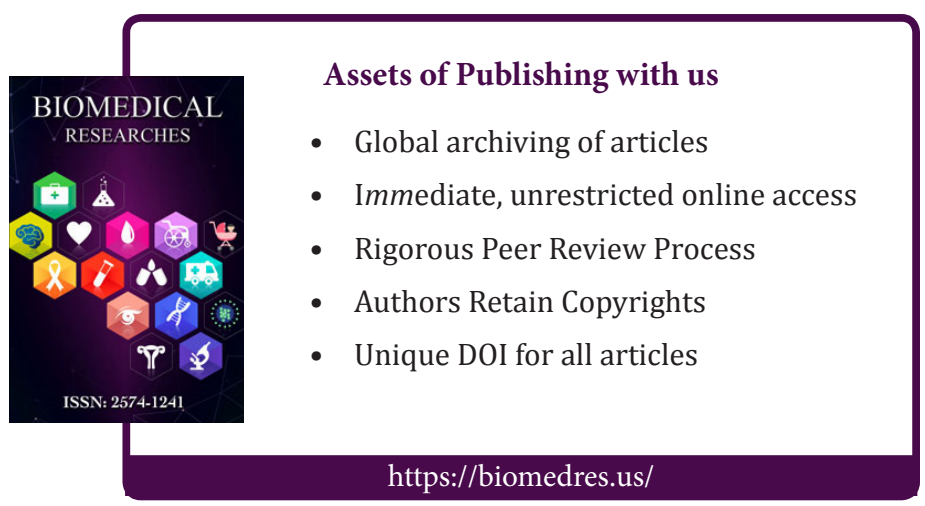

